\title{
Qualitative and quantitative polymerase chain reaction (PCR) for detection of Leishmania in spleen samples from naturally infected $\operatorname{dog} s^{2 / 2}$
}

\author{
Manuela da Silva Solcà ${ }^{\mathrm{a}}$, Carlos Eduardo Sampaio Guedes ${ }^{\mathrm{a}}$, Eliane Gomes Nascimento ${ }^{\mathrm{b}}$, \\ Geraldo Gileno de Sá Oliveira ${ }^{a}$, Washington Luis Conrado dos Santos ${ }^{\mathrm{a}}$, \\ Deborah Bittencourt Mothé Fraga ${ }^{\mathrm{a}, \mathrm{c}}$, Patrícia Sampaio Tavares Veras ${ }^{\mathrm{a}, *}$ \\ a Laboratório de Patologia e Biointervenção, Centro de Pesquisa Gonçalo Moniz - FIOCRUZ - Rua Waldemar Falcão 121, Candeal, 40296-710 Salvador, BA, \\ Brazil \\ b Centro de Referência em Doenças Endêmicas Pirajá da Silva-PIEJ, CSU, URBIS 1, Rua 3s/n, Jequié 45200-000, BA, Brazil \\ c Departamento de Medicina Veterinária Preventiva, Escola de Medicina Veterinária, Universidade Federal da Bahia, Av. Ademar de Barros 500, Salvador \\ 40170-000, Brazil
}

\section{A R T I C L E I N F O}

\section{Article history:}

Received 21 June 2011

Received in revised form 11 August 2011

Accepted 16 August 2011

\section{Keywords:}

Leishmania

Canine

PCR

Spleen

Diagnostic method

\begin{abstract}
A B S T R A C T
Because infected dogs are widely considered to be the main domestic reservoir for Leishmania infantum (syn Leishmania chagasi) parasites in Brazil, the diagnosis of canine visceral leishmaniasis (CVL) must be made both accurately and promptly. The present study attempted to standardize a conventional polymerase chain reaction (CPCR) protocol for the detection of $L$. infantum DNA in canine spleen samples. Quantitative PCR (qPCR) technique was used to confirm the presence of Leishmania DNA in the canine spleen fragments. A comparison was made between the efficacies of these molecular diagnostic techniques and conventional parasitological and serological methods. CPCR protocols for spleen samples were standardized using primers that amplify a $145 \mathrm{bp}$ fragment, located at the parasite kinetoplast minicircle. The genus specificity of the CPCR protocol was assessed by its inability to amplify the DNA of other common canine pathogens, such as Ehrlichia canis, Babesia canis, Toxoplasma gondii and Trypanosoma cruzi. CPCR protocol sensitivity was tested by assessing the reaction detection limit, determined to be $10 \mathrm{fg}$ of $L$. infantum reference strain DNA, which corresponds to a range of 0.03-0.1 parasites per fragment. Standardized cPCR protocol was used to detect the presence of Leishmania in 45 dog spleen samples. Our results showed that $40 \%$ of the spleen fragment cultures were positive for Leishmania parasites, $58 \%$ of the dog serum samples tested positive using ELISA, and parasite DNA was detected in $44 \%$ using qPCR, while $47 \%$ of the spleen samples using CPCR. Diagnostic methods performance was assessed and revealed a better degree of ascertainment for CPCR when compared to other diagnostic methods. The sensitivity of ELISA was $83.3 \%$, qPCR was $83.3 \%$, and cPCR was $88.9 \%$; PPV for ELISA was $57.7 \%$, qPCR was 75\% and cPCR was 76.2\%; the Kappa coefficients were found to be 0.40 (fair) for ELISA, 0.64 (substantial) for qPCR and 0.68 (substantial) for CPCR. In both oligosymptomatic and polysymptomatic dogs, CPCR revealed the better performance analysis when compared to other diagnostic methods. The findings presented herein establish CPCR as the most indicated test to detect Leishmania when compared to the other two diagnostic methods
\end{abstract}

\footnotetext{
is Support for this research was provided by FAPESB, INCT-CNPq, PDTIS.

* Corresponding author. Tel.: +55 7131762263 ; fax: +55 7131762290.

E-mail addresses: pveras@bahia.fiocruz.br, pstveras@gmail.com (P.S.T. Veras).
} 
evaluated. Despite the fact that the qPCR protocol provides a highly accurate quantification of parasites when targeting the SSU rRNA gene, this technique does not significantly improve the diagnosis of CVL when compared with the performance of the CPCR protocol, which focused on the kinetoplast minicircle.

(c) 2011 Elsevier B.V. All rights reserved.

\section{Introduction}

Zoonotic visceral leishmaniasis is a disease caused by Leishmania infantum (syn Leishmania chagasi) (Kuhls et al., 2011) a protozoan parasite that affects both dogs and humans (Lainson and Shaw, 1978). Leishmania is transmitted to human and animal hosts via Phlebotominae sand flies (Killick-Kendrick, 1999) and, due to a high degree of skin parasitism, domestic dogs are considered to be the main reservoir of this parasite (Deane and Deane, 1955; Dye, 1996; Gramiccia and Gradoni, 2005). Canine visceral leishmaniasis (CVL) can present as an asymptomatic infection or one with non-specific clinical signs, such as weight loss, alopecia, cutaneous lesions, conjunctivitis, onychogryphosis and lymphadenopathy (Ciaramella et al., 1997; Koutinas et al., 1999; Baneth et al., 2008).

Considering the growing prevalence of CVL, the development and implementation of more sensitive and specific diagnostic techniques is crucial to controlling this disease (Alvar et al., 2004). CVL diagnosis may prove challenging due to a variety of factors, such as a long course of infection (significant pre-patent period), a low parasite load in certain tissues and varied immune responses among resistant and susceptible dogs (Pinelli et al., 1999; Quinnell et al., 2001). The current gold standard diagnosis for visceral leishmaniasis $(\mathrm{VL})$ is parasite identification in the tissue of host species (Barrouin-Melo et al., 2004). However, the low degree of sensibility of this method, serological diagnostic tests, such as the indirect immunofluorescence assay (IFA) and the enzyme-linked immunosorbent assay (ELISA), are the methods generally used to detect VL (Alvar et al., 2004). However, the literature contains several reports of cross-reactivity when using these serological tests, specifically in sera from dogs infected with other common pathogens, such as Toxoplasma gondii, Ehrlichia canis and Trypanosoma cruzi, as well as other Leishmania species (Ferreira et al., 2007; Troncarelli et al., 2009). Furthermore, the failure of conventional methods to accurately diagnose asymptomatic dogs, when compared with biomolecular diagnostic techniques, has been reported (Solano-Gallego et al., 2001).

Conventional polymerase chain reaction (CPCR) analysis is a simple molecular technique for disease diagnosis, which has shown improved specificity and sensitivity over serological CVL diagnostic methods (Ashford et al., 1995; Moreira et al., 2007; Maia et al., 2009), since it allows for the detection of asymptomatic carriers (Berrahal et al., 1996; Lachaud et al., 2002).

A positive correlation exists between parasite load and disease manifestation in dogs with severe clinical signs (Manna et al., 2009), emphasizing the need for highly sensitive diagnostic techniques to detect infection in animals with less parasitization.
Reis et al. (2006) demonstrated that the spleen is one of the main sites where high parasite density is found during the course of CVL in both asymptomatic and symptomatic dogs. In addition, the spleen has been proposed as a key site for the accumulation and multiplication of Leishmania (Maia et al., 2009). These parasites are known to survive for extended periods in the spleen, as has been previously described in an experimental murine model employing infection with viscerotropic Leishmania (Lima et al., 2007). Previous studies have demonstrated that, as early as $96 \mathrm{~h}$ after experimental intradermal infection with L. donovani promastigotes, parasites were detected in canine draining lymph nodes and spleen (Saldarriaga et al., 2006). Moreover, another study found variable degrees of splenomegaly in the majority of CVL-infected dogs studied (Barrouin-Melo et al., 2006).

A previous study showed that splenic fine needle aspiration had a higher rate of parasite detection, in comparison with lymph node aspiration, using conventional parasitological techniques (Barrouin-Melo et al., 2004). Another study revealed that splenic aspiration appeared to be a more sensitive procedure than bone marrow aspiration, as well as being less painful and more tolerable in human patients (Sarker et al., 2004).

The present study aimed to standardize a CPCR protocol previously described by Lachaud et al. (2002) in order to detect parasite DNA in spleen fragments. The efficacy of conventional parasitological and serological diagnostic methods was compared to alternative molecular diagnostic techniques by testing the degree of specificity and sensitivity for CVL.

\section{Materials and methods}

\subsection{Sampling}

Forty-five canine spleen fragments from an endemic area for CVL were collected in 2006 during a compulsory euthanasia program involving stray dogs in the City of Jequié, located in the State of Bahia, Brazil. Each fragment was collected during necropsy using a sterile blade, and then was stored in liquid nitrogen until use. Prior to spleen fragment collection, the stray dogs were submitted to clinical, serological (ELISA) and parasitological (spleen culture) evaluation for CVL. The ELISA technique and canine spleen fragment culture test, the gold standard, were performed as described in previous studies (Paranhos-Silva et al., 1996; Baleeiro et al., 2006). The spleen fragments were cultured for a period of 4 weeks in Novy-MacNeal-Nicolle (NNN) biphasic medium at $23^{\circ} \mathrm{C}$, supplemented with 20\% FBS (Fetal Bovine Serum - Gibco BRL, New York, USA) and $100 \mu \mathrm{g} / \mathrm{mL}$ gentamicin to avoid contamination (Sigma Chemical Co., St. Louis, MO) (Barrouin-Melo et al., 2004). For parasite identification, microscopic observations 
were performed at weekly intervals for no less than 4 weeks. Dogs were clinically classified according to the presence or absence of common clinical signs of CVL, including weight loss, alopecia, cutaneous lesions, conjunctivitis, onychogryphosis and lymphadenopathy. According to Mancianti et al. (1988) in the absence of any observable signs, dogs were considered to be asymptomatic; in the presence of one to three clinical signs, dogs were classified as oligosymptomatic, in the presence of three or more signs, dogs were determined to be polysymptomatic.

\subsection{DNA extraction}

Frozen canine spleen fragments from euthanized dogs were thawed and DNA was extracted from a $20 \mathrm{mg}$ section using a DNeasy ${ }^{\circledR}$ Blood \& Tissue Kit (Qiagen, Hilden, Germany) in accordance with manufacturer protocols. Once extracted, the quality and concentration of each DNA sample was determined using a digital spectrophotometer (NanoDrop ${ }^{\circledR}$ ND-1000, Thermo Scientific, Wilmington, USA). The integrity of each DNA sample was evaluated using a $0.8 \%$ agarose gel. The DNA samples were then adjusted to concentration of $150 \mathrm{ng} / \mu \mathrm{l}$, aliquoted and stored at $-20^{\circ} \mathrm{C}$ until cPCR and quantitative PCR (qPCR) assays were performed.

\section{3. $C P C R$}

To detect parasite DNA in canine spleen samples, CPCR assays were performed using the technique for parasite DNA detection in canine blood samples described by Lachaud et al. (2002). Under standardized conditions, amplification was performed in a $20 \mu \mathrm{l}$ final volume containing: $150 \mathrm{ng}$ of DNA; dATP, dCTP, dGTP and dTTP at $10 \mu \mathrm{M}$ each (dNTP Mix ${ }^{\circledR}$ Promega, Madison, USA); $1.5 \mathrm{mM} \mathrm{MgCl} 2 ; 2 \mu$ PCR buffer at a concentration of $10 \times ; 1.25 \mathrm{U}$ of Taq DNA Polymerase $\left(\mathrm{GoTaq}^{\circledR}\right.$ DNA Polymerase $^{\circledR}$, Promega); $1 \mu \mathrm{M}$ of each of the following primers: 5'-CTTTTCTGGTCCCGCGGGTAGG-3' (RV1) and 5'CCACCTGGCCTATTTTACACCA-3' (RV2). All amplifications were performed using a thermal cycler (Mastercycler ${ }^{\circledR}$ Family, Eppendorf, Hamburg, Germany) as follows: 35 cycles at $94^{\circ} \mathrm{C}$ for $30 \mathrm{~s}$; annealing at $62^{\circ} \mathrm{C}$ for $30 \mathrm{~s}$; and an extension step at $72{ }^{\circ} \mathrm{C}$ for $90 \mathrm{~s}$. For negative controls, deionized water was used, as well as canine spleen fragment DNA ( $150 \mathrm{ng} / \mu \mathrm{l})$ from each of the uninfected dogs. L. infantum (MHOM/BR/2000/MER2) DNA (10 ng/ $\mu \mathrm{l})$ was used as a positive control in each reaction.

The reaction products were separated by electrophoresis in a $2 \%$ agarose gel for $1 \mathrm{~h} 40 \mathrm{~min}$ at $140 \mathrm{~V}, 240 \mathrm{~mA}$ in a $0.5 \times$ TBE buffer [0.04 M Tris-borate-HCl (JTBaker, MEX, MEX) with $10 \mathrm{mM}$ EDTA (Invitrogen, Carlsbad, CA, USA)]. Gels were stained in a solution containing $0.5 \mu \mathrm{g} / \mathrm{mL}$ ethidium bromide (Sigma, St. Louis, MO, USA) and distilled water. Gel images were captured under UV light (Gel Doc, Bio-Rad, CA, USA) (Schriefer et al., 2004).

\section{4. $C P C R$ standardization}

Assay standardization was performed in order to adapt the previously described PCR technique (Lachaud et al., 2002) used to analyze DNA taken from human blood samples to our technique, which obtained DNA from canine spleen fragments. CPCR specificity was assessed by performing amplification reactions using DNA samples from pathogens other than L. infantum; Leishmania major (MHOM/IR/-/173), Leishmania amazonensis (MHOM/BR/88/BA125), E. canis, B. canis, T. gondii, and T. cruzi.

Fifteen healthy dogs were raised at the CPqGM-FIOCRUZ experimental kennel in Salvador, Brazil, a location known to be negative for parasite transmission. Sera from all 15 dogs tested negative using ELISA (Paranhos-Silva et al., 1996) and their spleen cultures were also found to be negative for parasite growth. Splenic aspirate DNA samples from 15 healthy dogs were used to test whether CPCR reactions amplified targets other than parasite DNA. Protocol sensitivity was assessed by performing: (a) serial dilutions of DNA samples from positive controls, ranging from 10 to $200 \mathrm{ng}$; (b) contamination of splenic aspirate DNA $(150 \mathrm{ng})$ from 1 of the 15 healthy dogs with a serial dilution of parasite DNA, ranging from $10 \mathrm{ng}$ to $1 \mathrm{fg}$. Each PCR reaction was run using several controls: (a) for positive controls, (1) DNA samples ( $150 \mathrm{ng} / \mu \mathrm{l}$ ) from three dogs whose spleen fragment cultures tested positive for Leishmania sp., and (2) purified DNA from $L$. infantum $(10 \mathrm{ng} / \mu \mathrm{l})$ reference strain; (b) for negative controls, (1) splenic aspirate DNA $(100 \mathrm{ng} / \mu \mathrm{l})$ from 1 of the 15 healthy dogs, and (2) deionized water instead of DNA samples.

\subsection{Quantitative PCR ( $q P C R)$}

To quantify parasite DNA in canine spleen fragments, PCR assays were performed using a technique for parasite DNA quantification in human blood samples as described by Bossolasco et al. (2003) targeting a SSU rRNA gene sequence. The amplifications were performed at a final volume of $25 \mu \mathrm{l}$, containing: $5 \mu \mathrm{l}$ of $150 \mathrm{ng} / \mu \mathrm{l}$ of DNA spleen fragment diluted in deionized water and $20 \mu \mathrm{l}$ of PCR mixture, which consisted of $12.5 \mu \mathrm{l}$ of Universal Mastermix (Perkin-Elmer Applied Biosystems, Carlsbad, CA, USA) and forward primer 5'-AAGGTCAAAGAACAAGGCCAAG-3' (LEIF-forward) at a final concentration of $900 \mathrm{nM}$, reverse primer 5'-GCATCGGAGTCGG-3' (LEIR-reverse) at $300 \mathrm{nM}$, and a fluorogenic probe (5'-AGGAGCGTGTCCCCGTGGAGG$3^{\prime}$ ), which was synthesized using a FAM reporter molecule attached to the $5^{\prime}$ end, as well as a TAMRA quencher linked to the $3^{\prime}$ end (LEIP-probe) (Perkin-Elmer Applied Biosystems), at a final concentration of $200 \mathrm{nM}$. A standard curve was generated using tenfold serial dilutions of L. infantum DNA, ranging from $10^{6}$ to $10^{-1}$ parasites $/ \mathrm{mL}$, with each dilution performed in triplicate. Amplification was performed in quintuplicate for each sample, as well as a negative control, using an ABI Prism 5900 sequence detection system (Perkin-Elmer Applied Biosystems). The cycling parameters were $50^{\circ} \mathrm{C}$ for $2 \mathrm{~min}, 95^{\circ} \mathrm{C}$ for $10 \mathrm{~min}$, and 50 cycles at $95^{\circ} \mathrm{C}$ for $15 \mathrm{~s}$ and $60^{\circ} \mathrm{C}$ for $1 \mathrm{~min}$. A threshold cycle value $(\mathrm{Ct})$ was calculated for each sample by determining the point at which the fluorescence generated within a given reaction exceeded the threshold limit. The standard curve was drawn by plotting $\mathrm{Ct}$ values against the standardized parasite concentrations. The number of 

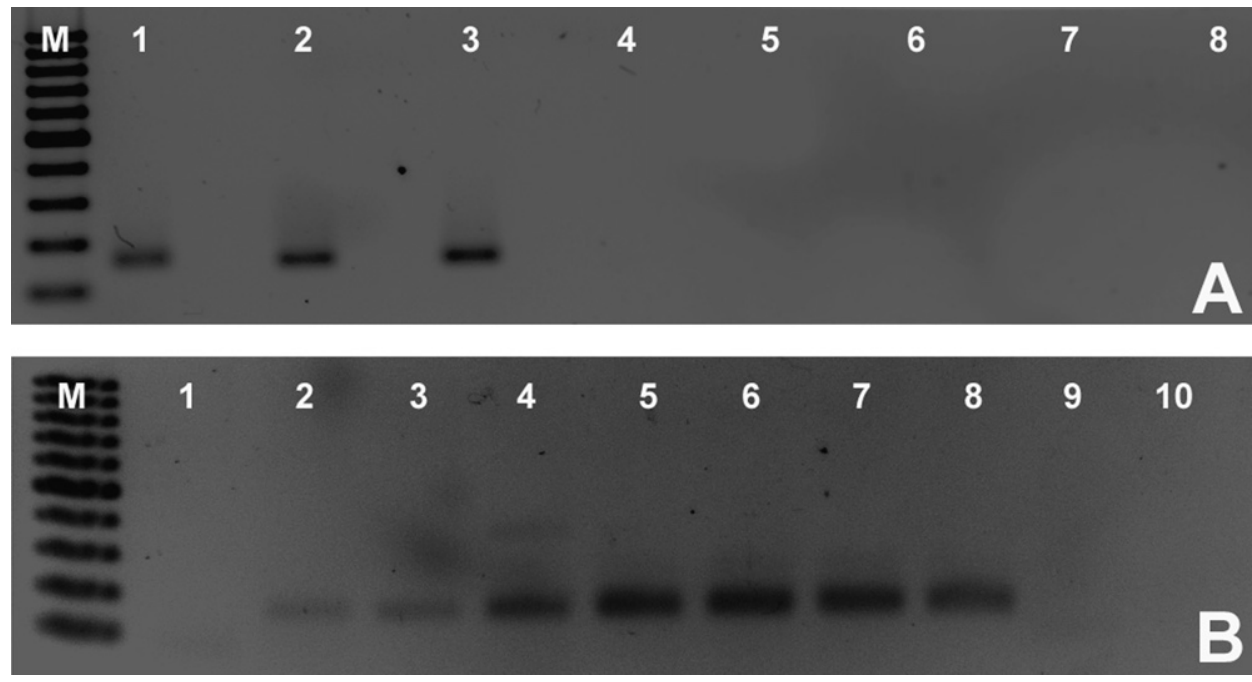

Fig. 1. Evaluation of $\mathrm{CPCR}$ protocol specificity and sensitivity. PCR products were size-separated by agarose gel electrophoresis and visualized using ethidium bromide staining. Each PCR reaction was run under standardized conditions as described in material and methods. Amplified PCR products using RV1 and RV2 primers correspond to the 145 base-pair band. (A) Agarose gel showing CPCR specificity. PCR products can be seen in lanes $1-3$, corresponding to $L$. infantum, L. amazonensis and L. major reference strain DNA, respectively; lanes 4-7 correspond to DNA isolate from T. cruzi, E. canis, B. canis and T. gondii. Lane 8 corresponds to negative control (water); $M=100$ bp DNA ladder marker. (B) Agarose gel showing cPCR sensitivity. PCR amplification was performed using healthy canine spleen DNA and varying concentrations of $L$. infantum reference strain DNA. Lanes $1-8$ correspond to $1 \mathrm{fg}, 10 \mathrm{fg}, 100 \mathrm{fg}, 1 \mathrm{pg}, 10 \mathrm{pg}$, $100 \mathrm{pg}, 1 \mathrm{ng}$, and $10 \mathrm{ng}$, respectively. Lane 9 corresponds to healthy dog DNA; lane 10 corresponds to negative control (water); $M=100 \mathrm{bp}$ DNA ladder marker.

parasites per sample was calculated as the mean of the values obtained in at least three out of the five sample aliquots. The method detection limit of the qPCR technique was estimated to be 0.5 parasites $/ \mathrm{mL}$.

\subsection{Decontamination procedures}

Due to the extremely high degree of sensitivity inherent in CPCR and qPCR techniques, special care was taken to avoid any contamination of the DNA samples during all procedures. To prevent carryover contamination by previously amplified DNA, filter tips were routinely used in all DNA extraction steps, as well as during CPCR and qPCR. In addition, the laminar flow hood and all utilized materials were decontaminated by UV radiation before and after each procedure. For each cPCR and qPCR amplification procedure, the PCR mixture was first placed in each well, followed by a dilution containing either spleen sample DNA, or L. infantum DNA. The cPCR protocol utilized a randomization of DNA samples and negative controls in order to confirm the absence of contamination.

\subsection{Statistical analysis}

Databases were built using Excel (Microsoft Office), and Epi-info ${ }^{\mathrm{TM}}$ 3.5.1 (Centers for Disease Control and Prevention - CDC, USA) was used to analyze and correlate clinical, serological, parasitological and bio-molecular parameters. The sensitivity and specificity of the CPCR protocol were assessed using canine spleen cultures as the "gold standard" for $L$. infantum parasite detection (Barrouin-Melo et al., 2004). Sensitivity and specificity percentages were calculated using a $2 \times 2$ contingency table which represents the distribution of positive and negative test results.
Differences between the sensitivity and specificity of each diagnostic test were assessed using the $\chi^{2}$-test ( $p$-value $<0.05$ ). The Kappa coefficient was calculated for each of the diagnostic methods with a 95\% confidence interval (CI). This coefficient was used to test agreement between the diagnostic methods and was interpreted according to Landis and Koch (1977): 1.00-0.81 almost perfect, 0.80-0.61 substantial, 0.60-0.41 moderate, 0.40-0.21 fair and $\leq 0.20$ slight. Additionally, positive predictive values (PPV) and negative predictive values (NPV) were measured for each of the diagnostic methods ( $p$-value $\leq 0.05$ ).

\section{Results}

\section{1. $C P C R$ protocol standardization}

The specificity of the established CPCR protocol was assessed using RV1 and RV2 primers to amplify DNA from T. cruzi, E. canis, B. canis and T. gondii, which did not amplify any fragments (Lanes 4-7 in Fig. 1A), while these same primers successfully amplified a 145 bp fragment of Leishmania spp. DNA (Lanes 1-3, Fig. 1A). No amplification was observed in lane 8 , which refers to the negative control.

The cPCR detection limit was $10 \mathrm{fg}$ of L. infantum DNA on agarose gel in lanes $1-8$ correspond to $1 \mathrm{fg}, 10 \mathrm{fg}, 100 \mathrm{fg}$, $1 \mathrm{pg}, 10 \mathrm{pg}, 100 \mathrm{pg}, 1 \mathrm{ng}$, and $10 \mathrm{ng}$, respectively (Fig. 1B). No amplification occurred in lane 1 , which corresponds to $1 \mathrm{fg}$ of $L$. infantum reference strain DNA, nor in lane 9, which refers to a healthy dog DNA sample. No amplification was observed in lane 10 , which corresponds to water as a negative control (Fig. 1B). As DNA spleen samples at a concentration of $150 \mathrm{ng}$ yielded the clearest band patterns, this DNA concentration was used for the cPCR assay (data not shown). When $150 \mathrm{ng}$ of healthy canine spleen 
Table 1

Comparison of diagnostic methods and clinical evaluation.

\begin{tabular}{|c|c|c|c|c|c|}
\hline \multirow[t]{2}{*}{ Clinical evaluation } & \multicolumn{5}{|c|}{ Diagnostic test positivity rate $n^{\mathrm{a}}(\%)$} \\
\hline & Culture & ELISA & CPCR & qPCR & Negative $^{\mathrm{b}}$ \\
\hline Asymptomatic & $1 / 8(12.5)$ & $2 / 8(25.0)$ & $2 / 8(25.0)$ & $1 / 8(12.5)$ & $4 / 8(50.0)$ \\
\hline Oligosymptomatic & $9 / 26(34.6)$ & $14 / 26(46.2)$ & $10 / 26(38.5)$ & $11 / 26(42.3)$ & $7 / 26(27.0)$ \\
\hline Polysymptomatic & $8 / 11(72.7)$ & $10 / 11(90.9)$ & $9 / 11(81.8)$ & $8 / 11(72.7)$ & $1 / 11(9.0)$ \\
\hline
\end{tabular}

a Number of positive dogs.

b Dogs tested negative for all diagnostic tests.

DNA was added to the PCR mixture, the detection limit of L. infantum reference strain DNA was similar to that of parasite DNA alone (10 fg, data not shown). No amplification was observed in any of the CPCR reactions using the 15 DNA spleen samples from the uninfected dogs (data not shown).

\subsection{Comparison of diagnostic methods and clinical evaluation}

Leishmania parasites were found in 40\% (18/45) of the canine spleen cultures. Anti-Leishmania antibodies were found in 58\% (26/45) of canine serum samples using ELISA. Parasite DNA was detected in 44\% (20/45) of the spleen fragments using qPCR, and in 47\% (21/45) using cPCR. Thirty-two out of a total of 45 dogs tested positive for CVL (71\%) using at least one of these four diagnostic methods. Twelve dogs had positive test results from only one of the diagnostic tests: parasites were identified in the spleen cultures of two dogs (4\%), eight dogs (18\%) tested positive using ELISA, a spleen fragment from one dog tested positive using qPCR (2\%), and another was positive using CPCR (2\%).

Clinical evaluation for signs of CVL found 18\% (8/45) of the dogs to be classified as asymptomatic, 58\% (26/45) as oligosymptomatic, and $24 \%(11 / 45)$ as polysymptomatic. Considering the eight asymptomatic dogs, four tested positive for CVL (50\%), only one dog (12.5\%) was positive using all four diagnostic methods, the others three were detected each one by a different diagnostic method (Table 1). Among the 26 oligosymptomatic dogs, nineteen (73\%) tested positive for CVL, five dogs (26\%) were positive using all four diagnostic tests, the others tested positive at least in one test (Table 1). Among the 11 polysymptomatic dogs, ten dogs (91\%) tested positive, seven of them (70\%) were positive using all four diagnostic tests, the others tested positive at least in one test (Table 1).

\subsection{Evaluation of diagnostic methods' performance}

Sensitivity, PPV and NPV for each test were estimated using parasite culture as the gold standard. ELISA sensitivity was 83.3\% (CI 57.7-95.6), qPCR was 83.3\% (CI 57.7-95.6) and CPCR was $88.9 \%$ (CI 63.9-98.1). PPV for ELISA was $57.7 \%$ (CI 37.2-76.0), qPCR was 75\% (CI 50.6-90.4) and cPCR was 76.2\% (CI 52.4-90.9). NPV for ELISA was $84.2 \%$ (CI 59.5-95.8), qPCR was 88\% (CI 66.7-96.8) and cPCR was 91.7\% (CI 71.5-98.5). The Kappa coefficient was calculated to measure the agreement index between the gold standard and each of the three diagnostic tests used. The Kappa
Table 2

Diagnostic method performance analysis

\begin{tabular}{lllll}
\hline Diagnostic method & Sensitivity (\%) & PPV (\%) & NPV (\%) & Kappa \\
\hline ELISA & 83.3 & 57.7 & 84.2 & 0.40 \\
qPCR & 83.3 & 75.0 & 88.0 & 0.64 \\
CPCR & 88.9 & 76.2 & 91.7 & 0.68 \\
\hline
\end{tabular}

Canine spleen cultures were used as the "gold standard". $\chi^{2}$-test $(p$ value $<0.05$ ).

coefficients were found to be 0.40 (fair) for ELISA, 0.64 (substantial) for qPCR and 0.68 (substantial) for cPCR (Table 2).

To evaluate diagnostic test performance with respect to clinical CVL evaluation, Kappa coefficients and PPVs were used to compare each diagnostic method to the gold standard (Table 3 ). The number of asymptomatic dogs was insufficient to perform statistical analyses $(n=4)$. In the oligosymptomatic group (dogs presenting at least three signs of CVL), PPV for ELISA was $43 \%$ and Kappa was 0.17 (slight), PPV for qPCR was 64\% and Kappa was 0.52 (moderate), and PPV for cPCR was 70\% and Kappa was 0.59 (moderate). In the polysymptomatic group (dogs presenting with more than three clinical signs of CVL) PPV for ELISA was $80 \%$ and Kappa was 0.42 (moderate), PPV for qPCR was $87.5 \%$ and Kappa was 0.54 (moderate), PPV for CPCR was $89 \%$ and Kappa was 0.74 (substantial).

\section{Discussion}

The present study endeavored to standardize a cPCR protocol for the detection of $L$. infantum DNA in canine spleen samples, based on the protocol described by Lachaud et al. (2002), previously used to detect $L$. infantum kDNA in human blood samples. The specificity of this CPCR protocol was tested by its inability to amplify DNA from pathogens other than trypanosomatids, such as $B$. canis, E. canis and T. gondii (Fig. 1A). These microorganisms are known to frequently infect dogs in Brazil and

Table 3

Diagnostic method performance analysis with respect to clinical CVL evaluation.

\begin{tabular}{|c|c|c|c|c|}
\hline \multirow[t]{2}{*}{ Diagnostic method } & \multicolumn{2}{|c|}{$\begin{array}{l}\text { Oligosymptomatic } \\
(n=26)\end{array}$} & \multicolumn{2}{|c|}{$\begin{array}{l}\text { Polysymptomatic } \\
(n=11)\end{array}$} \\
\hline & PPV & Карра & PPV & Kappa \\
\hline ELISA & $43.0 \%$ & 0.17 & $80.0 \%$ & 0.42 \\
\hline $\mathrm{qPCR}$ & $64.0 \%$ & 0.52 & $87.5 \%$ & 0.54 \\
\hline cPCR & $70.0 \%$ & 0.59 & $89.0 \%$ & 0.74 \\
\hline
\end{tabular}


may be responsible for serological cross-reactions in commonly used Leishmania tests, leading to false positives (Alves and Bevilacqua, 2004; Marcondes et al., 2011). Most commercially available immunological tests are not able to distinguish between different trypanosomatids, for example $T$. cruzi, from Leishmania (Troncarelli et al., 2009). In order to further test the cPCR protocol's specificity, $T$. cruzi DNA was subjected to the amplification protocol. The RV1 and RV2 primers were unsuccessful in amplifying $T$. cruzi DNA, demonstrating that these primers do not anneal with DNA from trypanosomatids other than Leishmania. By contrast, our cPCR protocol successfully amplified DNA from $L$. amazonensis and $L$. major reference strains (Fig. 1A).

In apparent contradiction to the results presented herein, Lima-Junior et al. (2009) detected no amplification of $L$. amazonensis and $L$. braziliensis DNA using RV1 and RV2 primers. These divergent results might be explained by differences in the assay protocols or strains used. Furthermore, the primers employed in the present study were designed to interact with a target region in the parasite kinetoplast minicircle, a highly conserved DNA region throughout the genus Leishmania (Sheline and Ray, 1989). The findings herein support the notion that RV1 and RV2 are not species-specific. New protocols capable of distinguishing between Leishmania species need to be developed, since some areas are endemic for both cutaneous and visceral forms of the disease (Coutinho et al., 1985; Madeira et al., 2006).

CPCR protocol sensitivity was tested by assessing the reaction detection limit, determined to be $10 \mathrm{fg}$ of $L$. infantum reference strain DNA. Similar results were obtained when reference strain DNA was mixed with spleen fragment DNA from a healthy dog (Fig. 1B). This limit of DNA concentration corresponds to a range of 0.03-0.1 parasites per fragment (Vitale et al., 2004; Quaresma et al., 2009), ensuring successful DNA detection in samples with low parasite burden, such as those found in asymptomatic or in the recently classified category of exposed animals (Leontides et al., 2002; Manna et al., 2009; Paltrinieri et al., 2010). To further assess protocol sensitivity, cPCR reactions were performed using varying amounts of splenic DNA from infected dogs. Again, no amplification was observed in reactions with less than $10 \mathrm{fg}$ of DNA. The amplification products obtained using 150 and $200 \mathrm{ng}$ of splenic DNA from infected dogs yielded the clearest band patterns, while those from a $100 \mathrm{ng}$ concentration were less clear (data not shown). DNA concentrations greater than $150 \mathrm{ng}$ were discarded in order to avoid CPCR reaction inhibitors.

The ELISA diagnostic test method had the highest positivity rate of the four tests, with $58 \%$ of all dogs testing positive, while the spleen culture test had the lowest rate of positivity, $40 \%$. It is possible that the elevated positivity rate associated with ELISA is due to the fact that stray dogs were employed in the present study, which may have been infected with pathogens other than Leishmania, leading to cross-reaction results (Lira et al., 2006). Our laboratory is currently conducting experiments using $\mathrm{CPCR}$ protocols to detect hemoparasitosis infection in dogs suspected for CVL. The notion that serum cross-reactivity is occurring in our analysis is supported by the finding of a low PPV (57.7\%) for ELISA (Table 2).

Performance analysis of $\mathrm{CPCR}$ found that this protocol had the highest Kappa coefficient (0.68), highest PPV (76.2\%) and highest rate of sensitivity (88.9\%) in comparison to the other diagnostic tests (Table 2). The literature contains several reports of higher qPCR sensitivity in relation to cPCR or ELISA (Francino et al., 2006; Quaresma et al., 2009). However, depending on the selected DNA target region, as well as the pair of primers used (Bastien et al., 2008), qPCR is not always more sensitive than CPCR. Several protocols targeting genomic or kinetoplast DNA (kDNA) have been developed for CVL (Solano-Gallego et al., 2009). Due to a high number of target copies, conventional assays based on kDNA are considered to be the most sensitive for CVL detection (Cortes et al., 2004; Gomes et al., 2008). When qPCR protocols target a less repetitive sequence, such as SSU rRNA, they exhibit a lower degree of sensitivity than CPCR protocols which employ the kinetoplast minicircle as a target.

As expected, the positivity rate of all four diagnostic tests used in this study increased in accordance with the severity of clinical manifestation (Table 1). Data in the present study show a low rate of diagnostic test sensitivity among the asymptomatic dogs, which underscores the need to use more than one test to confirm Leishmania detection. However, a single diagnostic test was shown to adequately confirm parasite infection among the oligosymptomatic and polysymptomatic dogs. In both of these groups, the performance analysis of $\mathrm{CPCR}$ revealed a better degree of ascertainment when compared to other diagnostic methods (Table 3).

One of the major concerns surrounding the use of spleen aspiration is the risk of severe bleeding and even death (Léveillé et al., 1993), which can be controlled using abdominal ultrasonography (Watson et al., 2010), thereby minimizing risk to the animal. In fact, BarrouinMelo et al. (2006), in an attempt to verify the safety of fine-needle spleen aspiration, reported no adverse incidents when conducting this procedure in over 200 dogs. Spleen aspirate appeared to be better tolerated than lymph node aspiration, even in the most severely affected dogs, which exhibited severe anemia and cachexia (BarrouinMelo et al., 2004).

One of the limitations regarding the use of molecular analysis to diagnose Leishmania is the fact that, compared to conventional serological tests, these techniques are considerably more expensive (Maia et al., 2009). However, the authors chose to employ molecular diagnosis for Leishmania as a confirmative test due to the greater sensitivity and specificity of CPCR and qPCR compared to serological testing.

The findings presented herein establish CPCR as the most indicated test to detect Leishmania when compared to the other two diagnostic methods evaluated. Despite the fact that the qPCR protocol provides a highly accurate quantification of parasites when targeting the SSU rRNA gene, this technique does not significantly improve the diagnosis of CVL when compared with the performance of the CPCR protocol that targets the kinetoplast minicircle and has the additional advantage to be cheaper than qPCR. 


\section{Conclusion}

The standardized CPCR protocol using canine spleen fragment samples was shown to be a sensitive and efficient tool for the diagnosis of Leishmania infection.

\section{Conflict of interest}

The authors declare that there are no conflicts of interest exist in the present study.

\section{Ethics committee approval}

The present study was approved by the Ethics Committee for Animal Experimentation of CPqGM-FIOCRUZ, protocol CEUA 040/2005.

\section{Acknowledgements}

The authors would like to thank Andris K. Walter for providing English revision and consulting services. This work was supported by grants and fellowships from FAPESB (Fundação de Amparo a Pesquisa no Estado da Bahia) and CNPq (Conselho Nacional de Pesquisa e Desenvolvimento). Veras, PST holds a grant from CNPq for productivity in research (306672/2008-1).

\section{References}

Alvar, J., Canavate, C., Molina, R., Moreno, J., Nieto, J., 2004. Canine leishmaniasis. Adv. Parasitol. 57, 1-88.

Alves, W.A., Bevilacqua, P.D., 2004. Quality of diagnosis of canine visceral leishmaniasis in epidemiological surveys: an epidemic in Belo Horizonte, Minas Gerais, Brazil, 1993-1997. Cad. Saude Publica 20, 259-265.

Ashford, D.A., Bozza, M., Freire, M., Miranda, J.C., Sherlock, I., Eulalio, C., Lopes, U., Fernandes, O., Degrave, W., Barker Jr., R.H., et al., 1995. Comparison of the polymerase chain reaction and serology for the detection of canine visceral leishmaniasis. Am. J. Trop. Med. Hyg. 53, 251-255.

Baleeiro, C.O., Paranhos-Silva, M., dos Santos, J.C., Oliveira, G.G., Nascimento, E.G., de Carvalho, L.P., dos-Santos, W.L., 2006. Montenegro's skin reactions and antibodies against different Leishmania species in dogs from a visceral leishmaniosis endemic area. Vet. Parasitol. 139, 21-28.

Baneth, G., Koutinas, A.F., Solano-Gallego, L., Bourdeau, P., Ferrer, L., 2008. Canine leishmaniosis-new concepts and insights on an expanding zoonosis: part one. Trends Parasitol. 24, 324-330.

Barrouin-Melo, S.M., Larangeira, D.F., Trigo, J., Aguiar, P.H., dos-Santos, W.L., Pontes-de-Carvalho, L., 2004. Comparison between splenic and lymph node aspirations as sampling methods for the parasitological detection of Leishmania chagasi infection in dogs. Mem. Inst. Oswaldo Cruz 99, 195-197.

Barrouin-Melo, S.M., Larangeira, D.F., de Andrade Filho, F.A., Trigo, J., Juliao, F.S., Franke, C.R., Palis Aguiar, P.H., Conrado dos-Santos, W.L., Pontesde-Carvalho, L., 2006. Can spleen aspirations be safely used for the parasitological diagnosis of canine visceral leishmaniosis? A study on asymptomatic and polysymptomatic animals. Vet. J. 171, 331-339.

Bastien, P., Procop, G.W., Reischl, U., 2008. Quantitative real-time PCR is not more sensitive than "conventional" PCR. J. Clin. Microbiol. 46, 1897-1900.

Berrahal, F., Mary, C., Roze, M., Berenger, A., Escoffier, K., Lamouroux, D., Dunan, S., 1996. Canine leishmaniasis: identification of asymptomatic carriers by polymerase chain reaction and immunoblotting. Am. J. Trop. Med. Hyg. 55, 273-277.

Bossolasco, S., Gaiera, G., Olchini, D., Gulletta, M., Martello, L., Bestetti, A., Bossi, L., Germagnoli, L., Lazzarin, A., Uberti-Foppa, C., Cinque, P., 2003. Real-time PCR assay for clinical management of human immunodeficiency virus-infected patients with visceral leishmaniasis. J. Clin. Microbiol. 41, 5080-5084.
Ciaramella, P., Oliva, G., Luna, R.D., Gradoni, L., Ambrosio, R., Cortese, L., Scalone, A., Persechino, A., 1997. A retrospective clinical study of canine leishmaniasis in 150 dogs naturally infected by Leishmania infantum. Vet. Rec. 141, 539-543.

Cortes, S., Rolao, N., Ramada, J., Campino, L., 2004. PCR as a rapid and sensitive tool in the diagnosis of human and canine leishmaniasis using Leishmania donovani s.l.-specific kinetoplastid primers. Trans. R. Soc. Trop. Med. Hyg. 98, 12-17.

Coutinho, S.G., Nunes, M.P., Marzochi, M.C., Tramontano, N., 1985. A survey for American cutaneous and visceral leishmaniasis among 1,342 dogs from areas in Rio de Janeiro (Brazil) where the human diseases occur. Mem. Inst. Oswaldo Cruz 80, 17-22.

Deane, L.M., Deane, M.P., 1955. Observações preliminares sobre importância comparativa do homem, do cão e da raposa (Lycalopex vetulus) como reservatórios da Leishmania donovani, em área endêmica de calazar no Ceará. O Hospital 48, 61-76.

Dye, C., 1996. The logic of visceral leishmaniasis control. Am. J. Trop. Med. Hyg. 55, 125-130.

Ferreira, E.d.C., de Lana, M., Carneiro, M., Reis, A.B., Paes, D.V., da Silva, E.S., Schallig, H., Gontijo, C.M., 2007. Comparison of serological assays for the diagnosis of canine visceral leishmaniasis in animals presenting different clinical manifestations. Vet. Parasitol. 146, 235-241.

Francino, O., Altet, L., Sanchez-Robert, E., Rodriguez, A., Solano-Gallego, L., Alberola, J., Ferrer, L., Sanchez, A., Roura, X., 2006. Advantages of realtime PCR assay for diagnosis and monitoring of canine leishmaniosis. Vet. Parasitol. 137, 214-221.

Gomes, Y.M., Paiva Cavalcanti, M., Lira, R.A., Abath, F.G., Alves, L.C., 2008. Diagnosis of canine visceral leishmaniasis: biotechnological advances. Vet. J. 175, 45-52.

Gramiccia, M., Gradoni, L., 2005. The current status of zoonotic leishmaniases and approaches to disease control. Int. J. Parasitol. 35, 1169-1180.

Killick-Kendrick, R., 1999. The biology and control of phlebotomine sand flies. Clin. Dermatol. 17, 279-289.

Koutinas, A.F., Polizopoulou, Z.S., Saridomichelakis, M.N., Argyriadis, D., Fytianou, A., Plevraki, K.G., 1999. Clinical considerations on canine visceral leishmaniasis in Greece: a retrospective study of 158 cases (1989-1996). J. Am. Anim. Hosp. Assoc. 35, 376-383.

Kuhls, K., Alam, M.Z., Cupolillo, E., Ferreira, G.E.M., Mauricio, I.L., Oddone, R., Feliciangeli, M.D., Wirth, T., Miles, M.A., Schönian, G., 2011. Comparative Microsatellite Typing of New World Leishmania infantum Reveals Low Heterogeneity among Populations and Its Recent Old World Origin. PLoS Negl. Trop. Dis. 5, e1155.

Lachaud, L., Chabbert, E., Dubessay, P., Dereure, J., Lamothe, J., Dedet, J.P., Bastien, P., 2002. Value of two PCR methods for the diagnosis of canine visceral leishmaniasis and the detection of asymptomatic carriers. Parasitology 125, 197-207.

Lainson, R., Shaw, J.J., 1978. Epidemiology and ecology of leishmaniasis in Latin-America. Nature 273, 595-600.

Landis, J.R., Koch, G.G., 1977. The measurement of observer agreement for categorical data. Biometrics 33, 159-174

Leontides, L.S., Saridomichelakis, M.N., Billinis, C., Kontos, V., Koutinas, A.F., Galatos, A.D., Mylonakis, M.E., 2002. A cross-sectional study of Leishmania spp. infection in clinically healthy dogs with polymerase chain reaction and serology in Greece. Vet. Parasitol. 109, 19-27.

Léveillé, R., Partington, B.P., Biller, D.S., Miyabayashi, T., 1993. Complications after ultrasound-guided biopsy of abdominal structures in dogs and cats: 246 cases (1984-1991). J. Am. Vet. Med. Assoc. 203, 413-415.

Lima, W.G., Oliveira, P.S., Caliari, M.V., Goncalves, R., Michalick, M.S., Melo, M.N., Tafuri, W.L., 2007. Histopathological and immunohistochemical study of type 3 complement receptors (CD11b/CD18) in livers and spleens of asymptomatic and symptomatic dogs naturally infected with Leishmania (Leishmania) chagasi. Vet. Immunol. Immunopathol. 117, 129-136.

Lima-Junior, M.S.d.C., Andreotti, R., Dorval, M.E.M.C., Oshiro, E.T., Oliveira, A.G., Matos, M.d.F.C., 2009. Identification of Leishmania species isolated in human cases in Mato Grosso do Sul, by means of the polymerase chain reaction. Rev. Soc. Bras. Med. Trop. 42, 303-308.

Lira, R.A., Cavalcanti, M.P., Nakazawa, M., Ferreira, A.G., Silva, E.D., Abath, F.G., Alves, L.C., Souza, W.V., Gomes, Y.M., 2006. Canine visceral leishmaniosis: a comparative analysis of the EIE-leishmaniosevisceral-canina-Bio-Manguinhos and the IFI-leishmaniose-visceralcanina-Bio-Manguinhos kits. Vet. Parasitol. 137, 11-16.

Madeira, M.F., Schubach, A., Schubach, T.M., Pacheco, R.S., Oliveira, F.S., Pereira, S.A., Figueiredo, F.B., Baptista, C., Marzochi, M.C., 2006. Mixed infection with Leishmania (Viannia) braziliensis and Leishmania (Leishmania) chagasi in a naturally infected dog from Rio de Janeiro, Brazil. Trans. R. Soc. Trop. Med. Hyg. 100, 442-445. 
Maia, C., Ramada, J., Cristovao, J.M., Goncalves, L., Campino, L., 2009. Diagnosis of canine leishmaniasis: conventional and molecular techniques using different tissues. Vet. J. 179, 142-144.

Mancianti, F., Gramiccia, M., Gradoni, L., Pieri, S., 1988. Studies on canine leishmaniasis control. 1. Evolution of infection of different clinical forms of canine leishmaniasis following antimonial treatment. Trans. R. Soc. Trop. Med. Hyg. 82, 566-567.

Manna, L., Reale, S., Vitale, F., Gravino, A.E., 2009. Evidence for a relationship between Leishmania load and clinical manifestations. Res. Vet. Sci. 87, 76-78.

Marcondes, M., Biondo, A.W., Gomes, A.A., Silva, A.R., Vieira, R.F., Camacho, A.A., Quinn, J., Chandrashekar, R., 2011. Validation of a Leishmania infantum ELISA rapid test for serological diagnosis of Leishmania chagasi in dogs. Vet. Parasitol. 175, 15-19.

Moreira, M.A., Luvizotto, M.C., Garcia, J.F., Corbett, C.E., Laurenti, M.D. 2007. Comparison of parasitological, immunological and molecular methods for the diagnosis of leishmaniasis in dogs with different clinical signs. Vet. Parasitol. 145, 245-252.

Paltrinieri, S., Solano-Gallego, L., Fondati, A., Lubas, G., Gradoni, L., Castagnaro, M., Crotti, A., Maroli, M., Oliva, G., Roura, X., Zatelli, A., Zini, E. 2010. Guidelines for diagnosis and clinical classification of leishmaniasis in dogs. J. Am. Vet. Med. Assoc. 1, 1184-1191.

Paranhos-Silva, M., Freitas, L.A., Santos, W.C., Grimaldi, G.J., Pontesde-Carvalho, L.C., Oliveira-dos-Santos, A.J., 1996. A cross-sectional serodiagnostic survey of canine leishmaniasis due to Leishmania chagasi. Am. J. Trop. Med. Hyg. 55, 39-44.

Pinelli, E., Rutten, V.P., Bruysters, M., Moore, P.F., Ruitenberg, E.J., 1999 Compensation for decreased expression of B7 molecules on Leishmania infantum-infected canine macrophages results in restoration of parasite-specific T-cell proliferation and gamma interferon production. Infect. Immun. 67, 237-243.

Quaresma, P.F., Murta, S.M., Ferreira Ede, C., da Rocha-Lima, A.C., Xavier, A.A., Gontijo, C.M., 2009. Molecular diagnosis of canine visceral leishmaniasis: identification of Leishmania species by PCR-RFLP and quantification of parasite DNA by real-time PCR. Acta Trop. 111, 289-294.

Quinnell, R.J., Courtenay, O., Davidson, S., Garcez, L., Lambson, B., Ramos, P., Shaw, J.J., Shaw, M.A., Dye, C., 2001. Detection of Leishmania infantum by PCR, serology and cellular immune response in a cohort study of Brazilian dogs. Parasitology 122, 253-261.
Reis, A.B., Martins-Filho, O.A., Teixeira-Carvalho, A., Carvalho, M.G. Mayrink, W., Franca-Silva, J.C., Giunchetti, R.C., Genaro, O. Correa-Oliveira, R., 2006. Parasite density and impaired biochemical/hematological status are associated with severe clinical aspects of canine visceral leishmaniasis. Res. Vet. Sci. 81, 68-75.

Saldarriaga, O.A., Travi, B.L., Park, W., Perez, L.E., Melby, P.C., 2006 Immunogenicity of a multicomponent DNA vaccine against visceral leishmaniasis in dogs. Vaccine 24, 1928-1940.

Sarker, C.B., Alam, K.S., Jamal, M.F., Rahman, S., Huq, M.H., Musa, A.K., Sutradhar, S.R., Talukder, S.I., Debnath, C.R., 2004. Sensitivity of splenic and bone marrow aspirate study for diagnosis of kala-azar. Mymensingh Med. J. 13, 130-133.

Schriefer, A., Schriefer, A.L., Goes-Neto, A., Guimaraes, L.H., Carvalho, L.P. Almeida, R.P., Machado, P.R., Lessa, H.A., de Jesus, A.R., Riley, L.W., Carvalho, E.M., 2004. Multiclonal Leishmania braziliensis population structure and its clinical implication in a region of endemicity for American tegumentary leishmaniasis. Infect. Immun. 72, 508-514.

Sheline, C., Ray, D.S., 1989. Specific discontinuities in Leishmania tarentolae minicircles map within universally conserved sequence blocks. Mol Biochem. Parasitol. 37, 151-157.

Solano-Gallego, L., Morell, P., Arboix, M., Alberola, J., Ferrer, L., 2001. Prevalence of Leishmania infantum infection in dogs living in an area of canine leishmaniasis endemicity using PCR on several tissues and serology. J. Clin. Microbiol. 39, 560-563.

Solano-Gallego, L., Koutinas, A., Miro, G., Cardoso, L., Pennisi, M.G., Ferrer, L., Bourdeau, P., Oliva, G., Baneth, G., 2009. Directions for the diagnosis, clinical staging, treatment and prevention of canine leishmaniosis. Vet. Parasitol. 165, 1-18.

Troncarelli, M.Z., Camargo, J.B., Machado, J.G., Lucheis, S.B., Langoni, H., 2009. Leishmania spp. and/or Trypanosoma cruzi diagnosis in dogs from endemic and nonendemic areas for canine visceral leishmaniasis. Vet. Parasitol. 164, 118-123.

Vitale, F., Reale, S., Vitale, M., Petrotta, E., Torina, A., Caracappa, S., 2004 TaqMan-based detection of Leishmania infantum DNA using canine samples. Ann. N.Y. Acad. Sci. 1026, 139-143.

Watson, A.T., Penninck, D., Knoll, J.S., Keating, J.H., Sutherland-Smith, J., 2010. Safety and correlation of test results of combined ultrasoundguided fine-needle aspiration and needle core biopsy of the canine spleen. Vet. Radiol. Ultrasound 52, 317-322. 